\title{
Exploring Crossmodal Interaction of Tactile and Visual Cues on Temperature Perception in Virtual Reality: a Preliminary Study
}

\author{
Helfenstein-Didier, CD, Clémentine \\ Univ Lyon, ENISE, LTDS, UMR 5513 CNRS, 58 rue Jean Parot, 42023 Saint-Etienne cedex 2, France, \\ clementine.didier@enise.fr
}

Dhouib, AD, Amira

National Engineering School (ENISE), 58 rue Jean Parot, 42023 Saint-Etienne cedex 2, France, amiradhouib@live.fr

Favre, FF, Florent

National Engineering School (ENISE), 58 rue Jean Parot, 42023 Saint-Etienne cedex 2, France

Pascal, JP, Jonathan

National Engineering School (ENISE), 58 rue Jean Parot, 42023 Saint-Etienne cedex 2, France

Baert, PB, Patrick

National Engineering School (ENISE), 58 rue Jean Parot, 42023 Saint-Etienne cedex 2, France, patrick.baert@enise.fr

\begin{abstract}
Thanks to the digital revolution, virtual reality (VR) has getting popularity due to its capacity to immerse users into virtual environments (VEs). VEs are typically limited to visual and auditory cues; however, recent results show that multiple sensory modalities increase the user's immersion. In this study, an experimental protocol is proposed to recreate multiple tactile, in particular thermal, sensations in VR. The aim is twofold: (1) studying the performance of different devices for creating warm and cold sensations with regards to their efficiency and acoustic disturbance; and (2) investigating the interdependency between visual and tactile stimuli in the perception of temperature. 14 participants performed two experimental studies. Our results show no acoustic disturbance of the materials used. Spot projector is more efficient than fan heater to create a warm sensation; fan + water spray is more efficient than fan alone to create cold sensation. Moreover, no significant contribution of visual cue on the thermal perception was found except for the extremely cold simulation (snow visualization and thermal stimulation performed with fan + water spray).
\end{abstract}

CCS CONCEPTS • Human-centered computing Interaction design • General and reference Cross-computing tools and techniques

Additional Keywords and Phrases: Virtual environment, Thermal sensation, Virtual reality

ACM Reference Format:

Helfenstein-Didier, CD, Clémentine, Dhouib, AD, Amira, Favre, FF, Florent, Pascal, JP, Jonathan, Baert, PB, Patrick. 2021. Exploring Crossmodal Interaction of Tactile and Visual Cues on Temperature Perception in Virtual Reality: a Preliminary Study: In SensoryX '21: Workshop on Multisensory Experiences, together with IMX 2021: ACM International Conference on Interactive Media Experiences. June 21-23, 2021. NY, USA.

Published in accordance with the terms of the Creative Commons Attribution 4.0 International Public License (CC BY 4.0). Permission to reproduce or distribute this work, in part or in whole, verbatim, adapted, or remixed, is granted without fee, provided that the appropriate credits are given to the original work, not implying any endorsement by the authors or by SBC.

2021 Brazilian Computing Society 


\section{INTRODUCTION}

In recent years, there has been an increasing interest in Virtual Reality (VR). This interest is reflected in the use of this technology in several fields like education, industrial maintenance, healthcare, etc. [1-3]. With the growth of the use of VR, companies and researchers are not anymore focusing exclusively on visual cues to make the Virtual Environments (VE) more realistic or to increase the user's immersion of the VE. In fact, stimulating the different human senses in VR represents a possible way to achieve these objectives. Obrist et al. [4] highlight the potential of designing multisensory experience leading to the creation of new products and experiences. Researchers investigate the effect of multisensory stimulation on different parameters (quality of experience, sense of presence, immersion, memory, etc.) [5-7]. 84.8\% of the studies that Melo et al. [3] analyzed show a positive impact of multisensory VR experiences. According to them, haptics is the most commonly used stimulus in multisensory VR systems (86.6\%).

Haptic cues include cutaneaous cues that allow us to detect stimuli such as touch, vibrations and temperature [8]. Some researches aim at implementing thermal cues in VR. There exist various non-contact thermal feedback [6, 9]. Cold cues is less studied as fans are more generally used to simulate wind than cold [10-12]. Contact thermal stimulations are also expanding [5, 13-14]. Others are very sophisticated [7, 15-16].

Although these devices are increasingly used, they focus on the impact of multisensorial cues on parameters such as quality of experience or sense of presence $[5,7,13]$. There exist few studies that evaluate the performance of new devices for warm and cold sensations and conclusions are heterogeneous [15-16]. To the best of our knowledge, there is not yet a proposal that assess the acoustic disturbance during the use of these devices. Motivated by this lack, the main objective of this research is to better understand the impact of acoustic disturbance on thermical sensation. Finally, we compare our proposal with respect to the existing studies

\section{METHODOLOGY}

We investigate the following research questions:

Q1. What is the performance of different devices for creating warm and cold sensations with regards to their efficiency and acoustic disturbance?

Q2. Is there any interdependency between visual and tactile stimuli in the perception of temperature?

\subsection{Participants}

Fourteen volunteers ( 7 males, 7 females) aged from 24 to 68 years (mean=37.5 \pm 10.97 ), wearing a t-shirt and pants, participated to our experiments. All of them have no or a limited experience with the VE. Volunteers participated after giving informed consent and did not receive any monetary compensation.

\subsection{Experimental Design}

The study was carried out for approximately $30 \mathrm{~min}$ per participant (from arrival to departure). Our study had 2 scenarios: scenario 1 thermic stimulation without a visual cue (black screen in the HMD), scenario 2 thermic stimulation with a visual cue (chimney for warm sensation, snowing mountains for cold sensation - available on steam VR). During each scenario, the same cold and warm stimulation are used. Different devices have been used in each test area to recreate the feeling of median/high cold, median/high warm (see Table 1). The initial room temperature $\left(22.88 \pm 1.09^{\circ} \mathrm{C}\right)$, hygrometry $(36.14 \pm 9.03 \%)$ and level of sound $(38.9 \pm 0.2 \mathrm{dBA})$ were measured before each experiment. All the devices were manually activated by the experimenter. 
Table 1: Characteristics of the used devices during the experiments

\begin{tabular}{|c|c|c|c|c|c|}
\hline Devices & & Characteristics & $\begin{array}{l}\text { Settings used for } \\
\text { experiments }\end{array}$ & $\begin{array}{l}\text { Sound level } \\
(\mathrm{dBA})\end{array}$ & $\begin{array}{l}\text { Speed of wind } \\
\mathrm{m} / \mathrm{s}\end{array}$ \\
\hline \multirow{2}{*}{$\begin{array}{l}\text { Heat } \\
\text { systems }\end{array}$} & Fan heater & $\begin{array}{l}-1000 \text { W (level 1) } \\
-2000 \text { W (level 2) }\end{array}$ & \multirow{2}{*}{$\begin{array}{l}\text { Position of device: } \\
\text { Pelvis height } \\
0.5 \mathrm{~m} \text { from the } \\
\text { participant }\end{array}$} & $48.9-50.5$ & $0-0.3$ \\
\hline & Spot projector & $\begin{array}{l}-1200 \mathrm{~W} \\
\text { - Produces radiation }\end{array}$ & & 39.0 & - \\
\hline \multirow[b]{2}{*}{$\begin{array}{l}\text { Cold } \\
\text { systems }\end{array}$} & Electric fan & $\begin{array}{l}-50 \mathrm{~W} \\
\text { - Two speed levels }\end{array}$ & \multirow{2}{*}{$\begin{array}{l}\text { Position of device: } \\
\text { Pelvis height } \\
1 \mathrm{~m} \text { from the participant }\end{array}$} & $\begin{array}{l}43.5-44.8(\text { level } 1) \\
51.5-53.8(\text { level } 2)\end{array}$ & $\begin{array}{l}0.7-1.6(\text { level } 1) \\
1.5-3(\text { level } 2)\end{array}$ \\
\hline & $\begin{array}{l}\text { Electric fan + } \\
\text { Evian sprayer }\end{array}$ & $\begin{array}{l}\text { - } 50 \text { W } \\
\text { - Two speed levels } \\
\text { - Generate humidity }\end{array}$ & & $\begin{array}{l}43.7-45.5(\text { level } 1) \\
51.0-53.9(\text { level } 2)\end{array}$ & $\begin{array}{l}0.7-1.6(\text { level } 1) \\
1.5-3(\text { level } 2)\end{array}$ \\
\hline
\end{tabular}

\{Cold area\}. Two set-up were tested to generate the cold stimuli: an electric fan (with two levels), and the same fan with a water spray. Level 1 corresponds to a speed of wind between 0.7 and $1.6 \mathrm{~m} / \mathrm{s}$; level 2 corresponds to a speed of wind between 1.5 and $3 \mathrm{~m} / \mathrm{s}$ when the fan and sprayer were placed at $1 \mathrm{~m}$ from the participants. Instantaneous level of sound was registered with a sonometer (see Table1).

$\{$ Warm area\}. An electric heater and a spot projector are used. All the devices were placed at pelvis height of the volunteer. The power level of the heater was modified. Level 1 and level 2 correspond to a speed of blowing air between 0 and $0.3 \mathrm{~m} / \mathrm{s}$ when the heater was placed at $0.5 \mathrm{~m}$ from the participants. Instantaneous level of sound was registered with a sonometer (see Table1).

After each stimulation exposure, participants were required to answer questions on thermal sensation and noise disturbance. Before starting, a thermal scale from 0 to 5 ( 0 refers to extremely cold, 5 refers to extremely warm) was showed to explain the scoring system. Participants answered the following questions:

How do you rate the thermal sensation? \{rate from 0 to 5$\}$. Did the noise bother you? \{answer yes or no\}.

\section{RESULTS}

We look into the performance of different devices for creating warm and cold sensations with regards to their efficiency and acoustic disturbance; and if there is any interdependency between visual and tactile stimuli in the perception of temperature. A Wilcoxon paired test was used to compare the sensation of cold, wind, or heat as function as used devices.

\subsection{Noise disturbance}

Sound levels during the experiment are reported in Table $1.100 \%$ of the participants reveal to have no sound disturbance during scenario 1 . Most of the participants were not bothered by the noise produced by the different devices (Table 2). The heater is noisier than other devices. $28.57 \%$ of volunteers were disturbed by its noise.

Table 2: Questionnaire results of question "Did the noise bother you?" \{answer yes or no\} in scenario 2

\begin{tabular}{cccccc}
\hline & Heater level 1 & Heater level 2 & Spot projector & Fan level 1 & Fan level 2 \\
\hline Yes & $28.57 \%$ & $28.57 \%$ & $0 \%$ & $0 \%$ & $7.14 \%$ \\
No & $71.43 \%$ & $71.43 \%$ & $100 \%$ & $100 \%$ & $92.86 \%$ \\
\hline
\end{tabular}




\subsection{Performance of different devices}

Cold devices. Figure 1a illustrates the mean values and standard deviations regarding the perception of temperature in both scenarios and for each level of fan. The level of cold feeling is increasing with the intensity (level) of the fan (scoring are decreasing). For example in scenario 1, cold sensation is at $2.18 \pm 0.32$ for level 1 and $1.82 \pm 0.42$ for level 2 (resp. $2.07 \pm 0.27$ and $1.82 \pm 0.32$ in scenario 2 ). Both levels are statistically different ( $\mathrm{p}=0.005$ for test 1 , and $\mathrm{p}=0.01$ for test 2 ).

Figure $1 \mathrm{~b}$ illustrates the mean values regarding the question "How do you rate the thermal sensation?" in both scenarios and for each level of fan+spray. The level of cold feeling is increasing with the intensity (level) of the fan, e.g. for scenario 1: $1.64 \pm 0.41$ for level 1 and $1.36 \pm 0.53$ for level 2 (respectively $1.36 \pm 0.41$ and $1.07 \pm 0.43$ in scenario 2 ). Both levels are statistically different ( $p=0.015$ for test 1 , and $p=0.025$ for test 2 ).

Warm devices. Figure 2 shows the mean values regarding question "How much do you feel heat?" for both scenarios. The warm sensation is higher with the projector than with the heater. For example, without VE (resp. with VE) means the sensation of heat is at $4.25 \pm 0.43$ for spot (resp. $4.36 \pm 0.53$ ) compared to $3.68 \pm 0.32$ and $4.21 \pm 0.32$ at level 1 and 2 of the heater (resp. $3.71 \pm 0.26$ and $4.32 \pm 0.37$ ). The differences are statistically different ( $p=0.002$ at level 1 of the heater, for test 1 and $p=0.005$ at level 1 of the heater).

The heating sensation significantly increases for both scenarios between heater level 1 and the other devices.

No difference $(p>0.05)$ was found, for both scenarios, between heater at level 2 and spot projector. Since spot projector has shown to produce no noise disturbance, which is not the case of fan heater level 2, those results thus suggest the spot projector as the recommended device for producing heat sensation.

\subsection{Effect of visual stimuli}

Cold simulation. As we can see in Figure 1, no significant difference was found between scenarios (with or without visual stimuli) for fan devices alone. However, the addition of spray in scenario 2 (with visual stimuli) leads to an increase of the cold sensation. Especially at level 2, a significant difference is found ( $p=0.025$ ).

Warm simulation. The warm sensation is slightly increasing with visual stimuli as mean scores are higher for scenario 2 than for scenario 1. However, those results show no statistical difference $(p>0.48)$ between both scenarios.
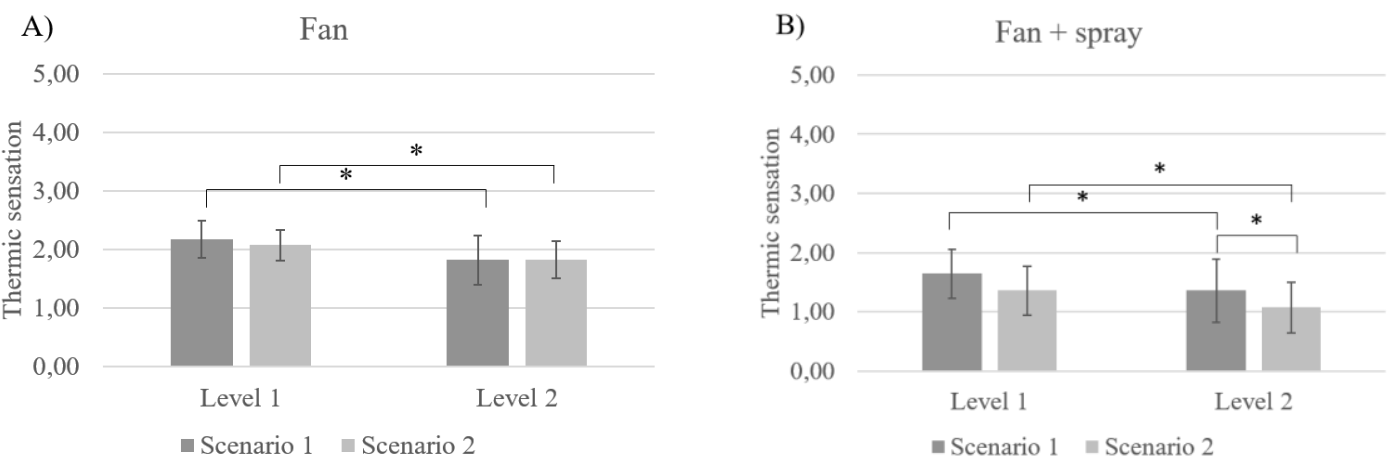

Figure 1: Perceived thermic sensation results for cold simulation, for both scenarios $(n=14)$ with black display (scenario 1$)$ and visual display (scenario 2). 0 represents "extremely cold", and 5 "extremely warm". 


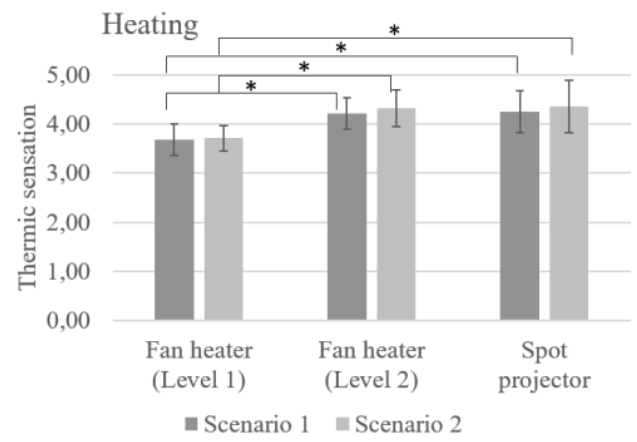

Figure 2: Perceived thermic sensation results for warm simulation, for both scenarios $(n=14)$

\section{DISCUSSION}

This study has enabled us to highlight notable aspects: 1) the performance of different devices for creating warm and cold sensations with regards to their efficiency and acoustic disturbance and 2) the limited interdependency between visual and tactile stimuli in the perception of temperature.

As the primary findings of our study, the way to produce cold has an impact on temperature perception. Significant results were observed: for scenario 1: $p=0.003$ for fan at level 1 and $p=0.004$ for fan at level 2; for scenario $2, p=0.001$ for fan at level 1 and 2 . The way to produce warm has an impact on the perceived temperature on both scenarios only when heater is at level 1 ( $p=0.002$ for scenario 1 and $p=0.005$ for scenario 2). No significant difference was observed between heater at level 2 and spot projector. However, some devices are noisier and can disturb volunteers in their immersion. For heat, the projector turned out to be quieter than the heater where $28.57 \%$ of volunteers reveals to be bothered by the noise when scenario 2 was performed. For cold, the reported noise disturbance was globally lower; a possible explanation could be that volunteers integrated the noise produced by the fan as wind in a snowing environment. Volunteers could less associate the noise from the heater in the chimney environment, so it was more disturbing.

Aside from this, it would have been interesting to investigate more deeply the effect of the way to produce heat. Despite no significant difference between heater at level 2 and projector, we decided to measure the temperature a posteriori. The thermometer was positionned at $0.5 \mathrm{~m}$ of the device, as in our scenarios. The temperature rise is faster and higher for the projector (more than $30^{\circ} \mathrm{C}$ after $30 \mathrm{~s}$ ) than for the heater $\left(24.7^{\circ} \mathrm{C}\right.$ after 30s). At that time, the temperature given by the heater is stable, in opposition to the one given by the projector which is still increasing. In our scenarios, we do not allow stabilization of the projector. Regarding measured temperatures, noise disturbance, and warm sensations, the projector seems to be more efficient than the heater. This can be explained by the way to produce heat. The projector emits heat by radiation, while the heater blows warm air. Concerning cold stimulation, fan + water spray is more efficient than fan alone.

In opposite of what could be expected, our results show no significant effect of the visual cue on the thermal sensation except for the extremely cold stimulation corresponding to snow visual with a cutaneous stimulation with fan+water. This result is in opposition with Günther et al. [15] who observe an impact of the visual stimuli on the perceived temperatures when considering the neutral thermal stimulus of $32.5^{\circ} \mathrm{C}$.

To compare our results with the one obtained by Günther et al. [15], we expressed all the thermic sensations (mean) on the same scale from 0 to 5 ( 0 corresponds to extremely cold, and 5 to extremely warm), as they were expressed on a scale from 0 to 8 in Günther et al. [15]. Although our setup is less sophisticated, it remains as 
efficient as "therminator" described in Günther et al. [15], as we have a device that has a same range of thermic sensation, except for the extremely cold sensation $\left(22.5^{\circ} \mathrm{C}\right)$.

\section{CONCLUSION AND FUTURE WORK}

The generation of different cutaneous sensations in VR is a challenging task. In this work, we have described a protocol whose goals were to assess the effect of the acoustic disturbance and the impact of visual stimuli on thermal perception. We conducted two experiments. Different devices have been used to recreate cold and warm sensations. Future work will investigate the inclusion of additional multisensory cues.

\section{ACKNOWLEDGMENTS}

The authors would like to thank Verène Tilly Djuigui Fotso, student who started to work on the project; and Guillaume Lavoué for his fresh, experienced and benevolent outlook on the topic.

\section{REFERENCES}

[1] Yasin Farmani and Robert J. Teather. 2018. Viewpoint Snapping to Reduce Cybersickness in Virtual Reality. In Proc. Graphics Interface Conference. Canadian Human-Computer Communications Society, Waterloo, CAN, 168-175. https://doi.org/10.20380/GI2018.23

[2] Weina Jin, Jianyu Fan, Diane Gromala, and Philippe Pasquier. 2018. AAutomatic Prediction of Cybersickness for Virtual Reality Games. In IEEE Games, Entertainment, Media Conference. IEEE, Galway, Ireland, 1-9. https://doi.org/10.1109/GEM.2018.8516469

[3] Miguel Melo, Guilherme Gonçalves, Pedro Monteiro, Hugo Coelho, José Vasconcelos-Raposo, and Maximino Bessa. 2020. Do Multisensory stimuli benefit the virtual reality experience? A systematic review. IEEE Transactions on Visualization and Computer Graphics. https://doi.org/10.1109/TVCG.2020.3010088

[4] Marianna Obrist, Elia Gatti, Emanuela Maggioni, Chi Thanh Vi, and Carlos Velasco. 2017. Multisensory Experiences in HCI. IEEE MultiMedia 24.https://doi.org/10.1109/MMUL.2017.33

[5] Felix Hülsmann, Julia Fröhlich, Nikita Mattar, and Ipke Wachsmuth. 2014. Wind and warmth in wirtual weality: implementation and evaluation. In Proc. Virtual Reality International Conference. ACM, New York,1-8. https://doi.org/10.1145/2617841.2620712

[6] Daisuke Iwai, Mei Aoki, and Kosuke Sato. 2019. Non-Contact Thermo-Visual Augmentation by IR-RGB Projection. IEEE Transactions on Visualization and Computer Graphics 25, 4 (2019), 1707-1716. https://doi.org/10.1109/TVCG.2018.2820121

[7] Nimesha Ranasinghe, Pravar Jain, Shienny Karwita, David Tolley, and Ellen Yi- Luen Do. 2017. Ambiotherm: Enhancing Sense of Presence in Virtual Reality by Simulating Real-World Environmental Conditions. In Proc. CHI'17. ACM, New York, $1731-1742$. https://doi.org/10.1145/3025453.3025723

[8] Francis McGlone and David Reilly. 2009. The cutaneous sensory system. Neuroscience \& Biobehavioral Reviews 34 (2009). https://doi.org/10.1016/j.neubiorev.2009.08.004

[9] Ping-Hsuan Han, Yang-Sheng Chen, Kong-Chang Lee, Hao-Cheng Wang, Chiao-En Hsieh, Jui-Chun Hsiao, Chien-Hsing Chou, and YiPing Hung. 2018. Haptic around: multiple tactile Sensations for immersive environment and interaction in virtual reality. In Proc. Symposium on Virtual Reality Software and Technology. ACM, New York, 1-10. https://doi.org/10.1145/3281505.3281507

[10] Mitsuru Minakuchi and Satoshi Nakamura. 2007. Collaborative Ambient Systems by Blow Displays. In Proc. International Conference on Tangible and Embedded Interaction. ACM, New York, 105-108. https://doi.org/10.1145/1226969.1226992

[11] Taeyong Moon and Gerard J. Kim. 2004. Design and Evaluation of a Wind Display for Virtual Reality. In Proc. Virtual Reality Software and Technology. ACM, New York, 122-128. https://doi.org/10.1145/1077534.1077558

[12] Jouke C. Verlinden, Fabian A. Mulder, Joris S. Vergeest, Anna de Jonge, Darina Krutiy, Zsuzsa Nagy, Bob J. Logeman, and Paul Schouten. 2013. Enhancement of Presence in a Virtual Sailing Environment through Localized Wind Simulation. Procedia Engineering 60 (2013). https://doi.org/10.1016/j.proeng.2013.07.050

[13] Dhruv Jain, Misha Sra, Jingru Guo, Rodrigo Marques, Raymond Wu, Justin Chiu, and Chris Schmandt. 2016. Immersive Terrestrial Scuba Diving Using Virtual Reality. In Proc. CHI'16. ACM, New York, 1563-1569. https://doi.org/10.1145/2851581.2892503

[14] Roshan Lalitha Peiris, Yuan-Ling Feng, Liwei Chan, and Kouta Minamizawa. 2019. ThermalBracelet: Exploring Thermal Haptic Feedback Around the Wrist. In Proc. CHI'19. ACM, New York, 1-11.

[15] Sebastian Günther, Florian Müller, Dominik Schön, Omar Elmoghazy, Max Mühlhäuser, and Martin Schmitz. 2020. Therminator: Understanding the Interdependency of Visual and On-Body Thermal Feedback in Virtual Reality. In Proc. CHI'20. ACM, New York, 1-14. https://doi.org/10.1145/3313831.3376195

[16] Roshan Lalintha Peiris, Wei Peng, Zikun Chen, Liwei Chan, and Kouta Minamizawa. 2017. ThermoVR: Exploring Integrated Thermal Haptic Feedback with Head Mounted Displays. In Proc CHI'17. ACM, New York, 5452-5456. https://doi.org/10.1145/3025453.3025824 